\title{
Development and feasibility of a web application to monitor patients' cancer-related pain
}

\author{
Wendy H. Oldenmenger ${ }^{1}$ • Mathilde A. G. Baan ${ }^{1}$ - Carin C. D. van der Rijt ${ }^{1,2}$
}

Received: 19 April 2017 / Accepted: 10 September 2017 / Published online: 19 September 2017

(C) The Author(s) 2017. This article is an open access publication

\begin{abstract}
Background In the outpatient setting, pain management is often inadequate in patients with cancer-related pain, because of patient- and professional-related barriers in communication and infrequent contacts. The internet may provide new opportunities for monitoring these patients.

Purpose The purpose of this study was to investigate whether internet monitoring of cancer-related pain in outpatients was feasible.

Methods We developed an internet application that contained a pain diary, eConsult, and patient pain education. In the pain diary, patients scored their pain intensity $(0-10$ Numeric Rating Scale) and analgesic use daily and their side effects twice a week. Feasibility was defined as the percentage of diaries patients completed during the first 6 weeks.

Results We included 100 outpatients. Sixteen were not evaluable due to cognitive problems (2); withdrawal of participation (2); internet problems (2), or because they were too ill (10). During the first 6 weeks, $60 \%$ of 84 evaluable patients completed their diary for at least $65 \%$ of the days (median number of diaries, 21 ; range, 3-42) and asked for a median of five eConsults (range, $0-37$ ). Patients most frequently used an eConsult for questions about pain or side effects, how to
\end{abstract}

Electronic supplementary material The online version of this article (https://doi.org/10.1007/s00520-017-3877-3) contains supplementary material, which is available to authorized users.

Wendy H. Oldenmenger

w.h.oldenmenger@erasmusmc.nl

1 Department of Medical Oncology, Erasmus MC Cancer Institute, PO Box 5201, 3008 AE Rotterdam, The Netherlands

2 Netherlands Comprehensive Cancer Organization, Utrecht, the Netherlands use their analgesics and to improve their self-management. Over the 6-week period, current pain intensity decreased from $3.3(\mathrm{SD}=2)$ to $2.5(\mathrm{SD}=1.6, p=0.005)$, and worst pain intensity decreased from $5.7(\mathrm{SD}=2)$ to $3.8(\mathrm{SD}=2.0$, $p<0.001$ ).

Conclusion Internet monitoring of pain is feasible in most outpatients with cancer-related pain. The frequent use of the pain diary in the majority of patients indicates that those patients felt confident with the regular assessment of pain.

Keywords Pain · Cancer · eHealth · Telemonitoring · Assessment $\cdot$ Self-management $\cdot$ Nursing

\section{Introduction}

In patients with cancer, pain is one of the most frequent and fearsome symptoms. In the ambulatory setting, half of the patients reported that they were in pain and approximately $20 \%$ that they had moderate to severe pain. Patients treated with a palliative intention reported significantly more frequent that they were in pain and that they had moderate to severe pain than patients treated with a curative intention $[1,2]$. In addition, pain management was inadequate in half of the patients with cancer-related pain [3, 4]. This seems to be related to both professional- and patient-related barriers regarding communication [5]. Professionals do not always ask for pain and do not always have adequate knowledge of pain management. Patients have various concerns and misconceptions about pain and analgesics, and the communication about their pain to professionals is poor [5].

This is especially important in the ambulatory setting. Pain assessment takes place at the outpatient clinic and relies on retrospective patient recall. As a result, timely adjustment of pain management is delayed. When patients are at home, they 
have to take a more active role in monitoring and communicating about their pain. Thereby, patients do not always know when to contact a professional and which professional they have to call.

The internet enables the monitoring of patient-reported symptoms in real-time. There is evidence for the added value of eHealth on cancer patients' knowledge and information competence [6]. However, the effect on other patient reported outcomes is inconsistent [6, 7]. Most studies only used the internet to collect patient data; they did not give feedback to the patient and therefore did not enable additional dialog between patients and health professionals nor did they provide supplementary education $[7,8]$. Additionally, most interventions were not able to respond to patient concerns in real-time $[8,9]$.

In general, in patients with cancer-related pain, frequent monitoring of their pain, side effects, and analgesic intake with personalized feedback seems valuable [10]. In the last few years, new technical possibilities have been developed to improve patient support, like online education about pain and analgesics to decrease patient-related barriers, and an eConsult function, like a chat or email function within a secured environment, to enhance the communication between patients and health professionals [6-8]. It is possible to combine these functions into a web application; however, hardly any study ever used a multimodal application. We therefore developed an internet application in which a patient pain diary, a patient education module, and an eConsult module were integrated. The aim of this study was to investigate whether internet monitoring of cancer-related pain in outpatients using the integrated web application was feasible. Secondary, we studied the course of patients' pain intensity during the first 6 weeks of the internet monitoring and evaluated patients' opinion about the web application.

\section{Methods}

The current study is a prospective cohort study to evaluate the development and thereafter, the feasibility of a multimodal web application in outpatients with cancer-related pain.

\section{Development of the web application}

For this study, we established a multidisciplinary project group, consisting of a medical oncologist, palliative care nurse specialists, a palliative care nurse researcher, and a personal health record (PHR) developer (www.myhealthmonitor.eu). The chief medical information officer and a hospital ICT consultant were involved as advisors.

The project group decided to develop a web application (www.pijn-kanker.nl) that can be used on different electronic devices, thereby enabling patients to use what they prefer, e.g., a PC, a laptop, a tablet, or a smartphone [11].

Based on the experiences in our earlier studies $[1,10,12]$ and after unstructured conversations with both health professionals and patients to evaluate their experiences with pain management in daily practice at the day care clinic, the project group decided that the web application should contain at least three components: (1) pain diary to monitor patients' pain, side effects, and analgesic intake, (2) pain education module to enhance patients' knowledge, and (3) eConsult module to enhance the communication between the patient and the health professional.

\section{Diary}

As patients gave us the feedback that they did not want to be remembered that they had cancer when they were at home, the premise was that the diary should be as short as possible, but contained enough information to be able to monitor these patients [13]. In the pain diary, patients scored their pain intensity and their analgesic use daily and their side effects twice a week (Table 1). The diary was accessible the whole day, so patients were free when to complete their diary. Pain intensity was measured with a numeric rating scale (NRS) from 0 (no pain) to 10 (worst pain imaginable) [14]. The nurse specialist entered the prescribed analgesics as recorded in the electronic patient record, into the web application. Hereby, patients saw a personalized schedule of their prescribed analgesics in their diary. Every day, patients could register whether they had used their around-the-clock analgesics in the last $24 \mathrm{~h}$ and how many of the as-needed analgesics they had taken in these $24 \mathrm{~h}$ (Table 1). To make sure that the prescribed analgesics were kept up to date, the last question in the diary was "Has a physician changed your prescription for analgesics in the last $24 \mathrm{~h}$ ?" When this question was answered positive, they got a message to send an eConsult with the details. The experienced opioid-related side effects were assessed using a categorical scale (none, mild, moderate, severe) (Table 1). All data were summarized in a table and also made visible in a composite graph.

\section{Patient education module}

Tailored web-based patient pain education was made available for all patients $[1,10]$. The main topics of this patient pain education were information about underlying reasons for pain, how to use the prescribed pharmacological pain treatment, side effects, and concerns and misconceptions related to pain and pain treatment (www.erasmusmc.nl/pijnbijkanker). 
Table 1 Diary questions

Every day

1. Please rate your pain by cycling the one number that tells how much pain you have right now?

$\begin{array}{llllllllllll}0 & 1 & 2 & 3 & 4 & 5 & 6 & 7 & 8 & 9 & 10\end{array}$

2. Please rate your pain by cycling the one number that best describes your pain at its worst in the last $24 \mathrm{~h}$ ?

$\begin{array}{llllllllllll}0 & 1 & 2 & 3 & 4 & 5 & 6 & 7 & 8 & 9 & 10\end{array}$

3. Did you experience any new pain in the last $24 \mathrm{~h}$ ?

Yes No

4. Did you use your around-the-clock analgesics in the past $24 \mathrm{~h}$ ?

e.g., Paracetamol, $1000 \mathrm{mg}, 4$ times daily $\quad$ Yes No

e.g., Oxycodone, $20 \mathrm{mg}, 2$ times daily $\quad$ Yes No

5. How many times did you use your analgesic in the past $24 \mathrm{~h}$ ?
e.g., Oxycodone IR, $10 \mathrm{mg}$, as needed
Choose:...

6. Was your pain relief sufficient?

Yes No

7. Has a physician changed your prescription for analgesics in the last $24 \mathrm{~h}$ ?

Yes No

8. Do you like to make a note for yourself?

Yes No

Only on Monday and Thursday

Did you experience any side effects? Please score below to what extent you suffer from:

Drowsiness

$\begin{array}{lll}\text { none mild moderate } & \text { severe } \\ \text { none mild moderate } & \text { severe } \\ \text { none mild moderate } & \text { severe } \\ \text { none mild moderate } & \text { severe } \\ \text { none mild moderate severe } \\ \text { none mild moderate severe } \\ \text { none mild moderate severe } \\ \text { none mild moderate severe } \\ \text { none mild moderate severe }\end{array}$

\section{eConsult module}

To enhance the communication between patients and health care professionals, we developed a secured email-like functionality within the web application. Nurse specialists could remind patients to complete their diaries or ask questions in response to the information in the diary. Patients could further explain their symptoms; but more importantly, in case of questions or uncertainties, patients could contact the nurse specialist via the eConsult. The nurse specialists answered these messages within one working day. All patients were informed that in case of an emergency they had to call their general practitioner or the hospital.

All the patient data were saved on secured servers conform the National regulations and with permission of our hospital chief medical information officer. The web application contained thresholds that generated alerts. Nurse specialists monitored the data based on an algorithm.
When patients gave answers outside a predefined acceptable range: scored their pain a 5 or higher, [15] scored their side effects moderate or severe, indicated that they did not use the prescribed analgesics, and answered that they had a new pain or when patients sent an eConsult, an email alert was sent to the nurse specialist who monitored that patient. Also when a health professional sent an eConsult to the patient, that patient got an email. The nurse specialist monitored all patients based on the email alerts; furthermore, they analyzed patients' situation once a week, using the weekly overview, a composite graph and summary table. When patients' pain management was inadequate, the nurse specialist contacted the patients via the eConsult, when more information was needed. First, they explained to patients how to deal with their pain and analgesics in their daily life. When necessary, the nurse specialists consulted the patient's own oncologist for advice. 


\section{Preparation}

The web application was pilot tested in three steps, and after every step, it was possible to adjust the application according to the guidance of the Medical Research Council [16]. First, we tested the application within the project group: to test whether the content of the application was as planned. Thereafter, three colleagues tested the application. As a result, we adapted the alerts. At first, the alerts were only visible within the web application. Based on this pilot, the alerts were emailed to the nurse practitioner who monitored that patient. Secondly, three chronic pain patients tested the application to study whether daily monitoring was possible; the content was clear to them and whether it was possible to login from home. As a result, we simplified the login. Patients' email address was used as their username, and patients had to create a password that adhered to the highest level of safety. Finally, we tested the web application in five patients with cancer-related pain. The central questions here were whether it was possible to include patients from the outpatient clinic and whether it was possible to monitor the patients as intended (Fig. 1). Based on this pilot, we concluded that it was possible to include patients with cancer-related pain for this study and that the logistics worked well.

\section{Cohort study}

After the pilot study, we planned a cohort study to investigate whether it was feasible to monitor patients' pain using the web application in daily practice. Between August 2013 and August 2015, patients were recruited via the outpatient oncology clinic of the Erasmus University Medical Center. Patients were eligible when they had a diagnosis of cancer, had cancerrelated pain, were living at home, understood enough Dutch to use the web application, had access to the internet, and provided informed consent. When patient's care was transferred to their general practitioner or a local hospital, patients were asked to stop using the web application.

Recruitment was conducted through the medical oncologists and the nurses working at the oncology day care unit. Informed consent was obtained from all individual participants included in the study. The investigator explained patients how to use the application, after which they were given a paper-copy user manual with screenshots. Patients were informed that their data would be used for this feasibility study. They could use the system for as long as they preferred, unless care was transferred to another setting. During the study, patients were monitored by nurse specialists' palliative care. When necessary, they contacted patient's own oncologist to discuss whether changes in pain treatment were required.

Various data were collected from the web application for this study: the percentage of diaries patients completed (feasibility), pain assessments, the frequency in which analgesics were changed, and the number of eConsult conservations. A random sample of 11 patients was semi-structured interviewed after 6 weeks, to get an insight in the usability of the web application and patients' satisfaction.

\section{Data analysis}

For this study, we considered the internet application feasible when $70 \%$ of the patients completed the diary for at least $65 \%$ of the days, as measured during the actual follow-up in the first 6 weeks. Based on this, with a power of 0.90 and an $\alpha=0.05$, a total sample of 81 evaluable patients was required. When patients were admitted to the hospital, the data gathered during hospital stay were excluded from the analysis.

Data were analyzed using Statistical Package SPSS version 22. The data during the first 6 weeks were used for the study of the feasibility; additionally, we studied the total period patients used the application. Descriptive statistics and frequency distributions were generated for patients' demographic and diary-related characteristics. To determine the differences in the pain intensities between baseline and 6 weeks, we used non-parametric tests (Wilcoxen Signed Rank test). A $p$ value of $<0.05$ (twosided) was considered statistically significant.

All interviews were audiotaped and were transcribed verbatim. We performed the analyses using the constant comparative method. The themes were independently derived from the interviews by two researchers independently.

\section{Results}

In total, we included 100 patients. Sixteen of them (16\%) were not evaluable because they were too ill to start the study $(n=10)$, withdrew participation $(n=2)$, had language/cognitive problems $(n=2)$, or internet problems ( $n=2$; Fig. 1). Characteristics of the 84 evaluable patients are summarized in Table 2 . The median age was 61 years (range, 25-76 years) and 48\% was male. Most patients (84\%) had advanced cancer, predominantly breast $(25 \%)$, gastrointestinal $(26 \%)$, or urogenital carcinoma $(16 \%)$. Ninety percent used strong opioids around-theclock, 95\% had a prescription for as-needed opioids, $87 \%$ had a prescription for non-opioids, and a third also used an adjuvant analgesic (Table 2).

During the first 6 weeks, patients completed a median of $72 \%$ of the diaries (range, $18-100 \%$ ). Sixty percent of the patients (confidence interval (CI) 45-69\%) completed their diary for at least $65 \%$ of the days. Patients did not complete their diaries every day. The main reasons for this were that they forgot it, had no or not so much pain, 
Fig. 1 Study flow chart

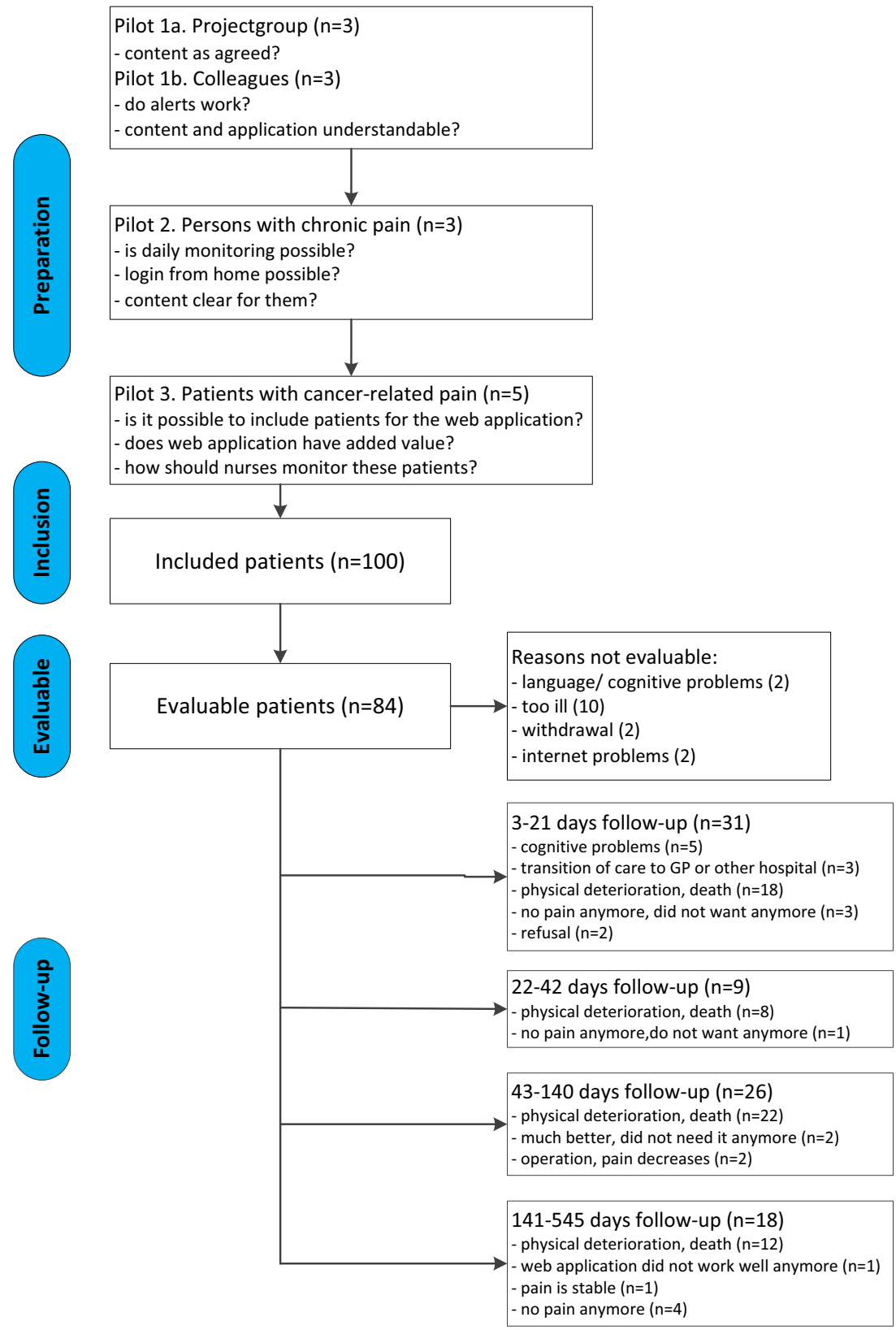

or were out for a day trip. In this period, 40 patients stopped using the web application due to several reasons: physical deterioration or death $(n=26)$, cognitive problems $(n=5)$, no pain anymore $(n=4)$, transition of care $(n=3)$, and refusal ( $n=2$; Fig. 1$)$. Patients completed a median of 21 diaries (range, 3-42) and asked for a median of five eConsults (range, 0-37). Patients most frequently used an eConsult for questions about pain, side effects, how to use their analgesics, and how to improve their self-management. Analgesics were changed twice (range, 1-8).

In the 48 patients with both a pain registration at baseline and at 6 weeks, current pain intensity decreased from
$3.3(\mathrm{SD}=2)$ to $2.5(\mathrm{SD}=1.6 ; p=0.005)$, and worst pain intensity decreased from $5.7(\mathrm{SD}=2)$ to $3.8(\mathrm{SD}=2.0$; $p<0.001$; Fig. 2).

Overall, patients used the web application during a median of 45 days (range, 1-545; Fig. 1), in which they completed a median of 29 diaries (range, 1-396). Patients asked for a median of five eConsults (range, 0-58). Analgesics were changed thrice (range, 1-11).

Patients were very satisfied using the web application (Table 3). Almost all patients were able to use the web application by themselves. Especially when patients became very ill, some spouses used the web application for the patients. 
Table 2 Patient characteristics

Evaluable patients $N=84$

\begin{tabular}{|c|c|}
\hline Sex, male & $40(48 \%)$ \\
\hline Age, years, mean (SD, range) & $59(11,25-76)$ \\
\hline \multicolumn{2}{|l|}{ Tumor } \\
\hline Breast & $21(25 \%)$ \\
\hline Gastrointestinal & $22(26 \%)$ \\
\hline Urogenital & $13(16 \%)$ \\
\hline Sarcoma & $8(10 \%)$ \\
\hline Head and neck & $4(5 \%)$ \\
\hline Lung & $2(2 \%)$ \\
\hline Gynecological & $3(4 \%)$ \\
\hline Others & $11(13 \%)$ \\
\hline Metastasis (yes) & $70(84 \%)$ \\
\hline $\begin{array}{l}\text { Current pain intensity, mean (SD) } \\
\text { Worst pain intensity, mean (SD) }\end{array}$ & $\begin{array}{l}3.4(2.0) \\
5.8(2.1)\end{array}$ \\
\hline $\begin{array}{l}\text { WHO step } 1 \\
\text { Paracetamol } \\
\text { NSAID }\end{array}$ & $\begin{array}{l}73(87 \%) \\
68 \\
32\end{array}$ \\
\hline WHO step 2 & 0 \\
\hline $\begin{array}{l}\text { WHO } 3 \text { opioid } \\
\text { Morphine } \\
\text { Fentanyl } \\
\text { Oxycodone } \\
\text { Hydromorphone }\end{array}$ & $\begin{array}{l}76(90 \%) \\
8 \\
38 \\
26 \\
4\end{array}$ \\
\hline $\begin{array}{l}\text { WHO } 3 \text { rescue medication } \\
\text { Morphine } \\
\text { Oxycodone IR } \\
\text { Hydromorphone IR } \\
\text { Fentanyl (nasal) } \\
\text { Fentanyl (sublingual) }\end{array}$ & $\begin{array}{l}80(95 \%) \\
13 \\
55 \\
3 \\
2 \\
7\end{array}$ \\
\hline $\begin{array}{l}\text { Adjuvant analgesics } \\
\text { Gabapentin } \\
\text { Pregabalin } \\
\text { Amitriptyline } \\
\text { Carbamazepine } \\
\text { Esketamine }\end{array}$ & $\begin{array}{l}27(32 \%) \\
4 \\
19 \\
2 \\
1 \\
1\end{array}$ \\
\hline MEDD, mg, median (range) & $90(15-540)$ \\
\hline
\end{tabular}

$S D$ standard deviation, $M E D D$ morphine equivalent daily dose, $m g$ milligram

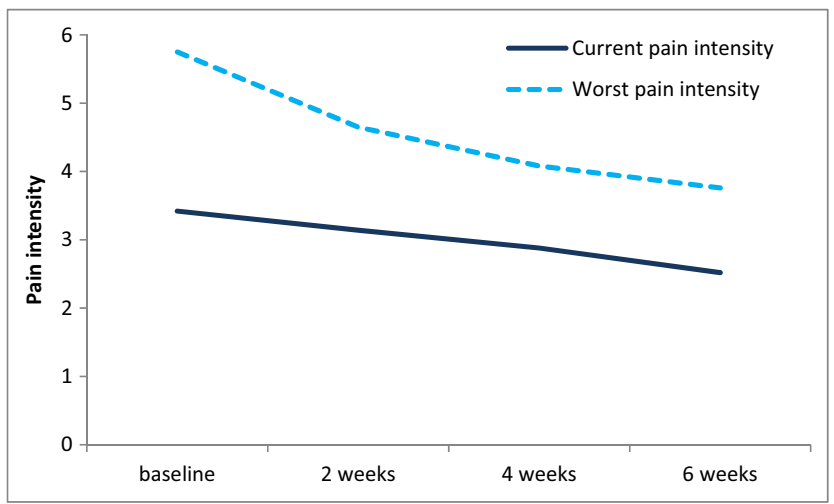

Fig. 2 Course of patients' pain intensity

\section{Discussion}

In daily practice, internet monitoring of pain seems to be feasible in most patients with cancer-related pain. Although we did not meet our primary endpoint of $60 \%$, instead of the predefined $70 \%$, the patients completed the diary for at least $65 \%$ of the days. The frequent use of the pain diary in the majority of patients indicates that those patients did not perceive barriers for the frequent assessment of pain and side effects. Especially eConsults were frequently asked, probably enhancing patients' self-management. Moreover, during the first 6 weeks, patients' pain intensity decreased significantly. However, in daily practice, patients did not complete their diaries every day. In the first 6 weeks, patients completed a median of $72 \%$ of the diaries, calculated over the actual period of patient follow-up. Patients were very positive about the web application and were satisfied with the time needed to complete the diary.

A multimodal web application is recommended for daily practice, because patients have different needs in supporting their self-management $[17,18]$. Patients may decide for themselves which kind of support they prefer to use at a specific moment. Some patients of the current study preferred the eConsult, to have a direct connection with a health professional. Other patients used the diary for a prolonged period (396 days). They also used the composite graph and summary table to have an overview over the last period to enhance their self-management. For example, after having a look at the summary table, one of the patients asked himself why he needed extra as-needed analgesics every Tuesday. He realized himself that the Tuesdays were too busy, and after adjusting his daily activities, his pain decreased and he did not need any extra analgesics anymore. Therefore, the web application

Table 3 Patients' opinions on feasibility, usability, and satisfaction with the web application

Web application

-All patients were positive about the web application

-Preference for different electronic devices: elderly patients preferred to use a PC or tablet (easier to read), while younger patients preferred a smartphone

-1 patient had occasional difficulties log in due to technical problems

-None of the patients had suggestions for adjustments

Content

-Home screen was very clear

-User manual gave confidence to use the web application

-Satisfied with the time needed to complete the pain diary $(<3 \mathrm{~min})$

-Inconvenient that it was not possible to complete the pain diary afterwards

-eConsult module had an added value

-eConsult module had a lower threshold than a phone

-Web application gained better support and communication 
seems feasible in daily practice, although not all patients completed their diaries every day.

Despite the fact that our included patients scored their pain as mild at baseline, their pain intensity decreased significantly during the first 6 weeks of the monitoring. Although this study was primary conducted to investigate the feasibility of the web application in patients with cancer-related pain, it is important that we also were able to show a significant change in a patient-reported outcome measurement such as pain. Most studies concerning eHealth and (web) applications did not measure any patient-reported outcome, or when they did, they did not find any difference [6-8].

We have chosen to develop a web application which can be used on multiple devices interchangeably (e.g., PC, laptop, tablet, or smartphone), allowing patients to use the device they prefer. In this study, elderly patients mainly used a tablet and younger patients $(<35$ years) preferred a smartphone. Most other studies concerning electronic symptom monitoring used a single device, mostly a PC or laptop [7, 8, 11]. Taylor et al. were the first who tested participants' preferences for the different modes in healthy volunteers [11]. Most people preferred the PC although it is less portable than the other devices. Short messaging service (SMS) was scored less appealing due to the costs and the inability to enter free text. Scrolling through the questions was cumbersome on particular smartphones and to a lesser extent on tablet computers [11]. They concluded that persons' preference for a particular device may be situation dependent, and therefore, future systems should enable various devices to be used exchangeable [11], as we did in our study.

\section{Strengths and limitations}

As all studies, this study has several limitations. We do realize ourselves that this kind of symptom monitoring is not possible for all patients, because not everyone has access to the internet. However, in the Netherlands, $97 \%$ of the citizens and $85 \%$ of the people $>65$ years have access to the internet [19]. Although we intended to include a representative sample of our ambulatory patients with cancer-related pain, we actually included a group of patients in the palliative phase of their disease with a short life expectancy, as is evident from the reasons why patients dropped out during follow-up. In addition, we only interviewed a random sample of the included patients to evaluate their opinion on the web application. In future studies, all patients should be evaluated structurally about their views. Besides this, in future studies, the feasibility should also be structurally evaluated in professionals. Furthermore, it is questionable whether only the questions from the diary are enough to monitor these patients. However, as shown in this study, the eConsult module has an added value to further personalize patients' monitoring. We showed a decrease in patients' pain intensity in the cohort study. A future RCT should demonstrate whether this reduction in pain intensity persists when compared with a control group.

\section{Conclusion}

Monitoring of pain via the internet is feasible in patients with cancer-related pain. In the future, it is important to investigate the efficacy and the cost-effectiveness of the web application in a randomized controlled trial.

Source of Funding This work was financially supported by a grant from the NutsOhra Foundation, Amsterdam, the Netherlands, and the Coolsingel Foundation, Rotterdam, the Netherlands, without any influence on study design, analysis, interpretation, or presentation.

\section{Compliance with ethical standards}

Conflict of interest The authors declare that they have no conflicts of interest.

Ethical approval The study protocol was approved by the Institutional Review Board of the Erasmus MC (MEC-2012-254).

Open Access This article is distributed under the terms of the Creative Commons Attribution-NonCommercial 4.0 International License (http:// creativecommons.org/licenses/by-nc/4.0/), which permits any noncommercial use, distribution, and reproduction in any medium, provided you give appropriate credit to the original author(s) and the source, provide a link to the Creative Commons license, and indicate if changes were made.

\section{References}

1. Oldenmenger WH, Witkamp FE, Bromberg JEC, Jongen JLM, Lieverse PJ, Huygen FJPM, Van Zuijlen L, Van der Rijt CCD (2016) To be in pain (or not): a computer enables outpatients to inform their physician. Ann Oncol 27(9):1776-1781. https://doi. org/10.1093/annonc/mdw250

2. van den Beuken-van Everdingen MH, Hochstenbach LM, Joosten EA, Tjan-Heijnen VC, Janssen DJ (2016) Update on prevalence of pain in patients with cancer: systematic review and meta-analysis. J Pain Symptom Manage 51(6):1070-1090 e1079

3. Enting RH, Oldenmenger WH, Van Gool AR, van der Rijt CC, Sillevis Smitt PA (2007) The effects of analgesic prescription and patient adherence on pain in a dutch outpatient cancer population. $\mathrm{J}$ Pain Symptom Manag 34(5):523-531

4. Deandrea S, Montanari M, Moja L, Apolone G (2008) Prevalence of undertreatment in cancer pain. A review of published literature. Ann Oncol 19(12):1985-1991

5. Oldenmenger WH, Sillevis Smitt PA, van Dooren S, Stoter G, van der Rijt CC (2009) A systematic review on barriers hindering adequate cancer pain management and interventions to reduce them: a critical appraisal. Eur J Cancer 45(8):1370-1380

6. Slev VN, Mistiaen P, Pasman HR, Verdonck-de Leeuw IM, van Uden-Kraan CF, Francke AL (2016) Effects of eHealth for patients and informal caregivers confronted with cancer: a meta-review. Int J Med Inform 87:54-67 
7. Dickinson R, Hall S, Sinclair JE, Bond C, Murchie P (2014) Using technology to deliver cancer follow-up: a systematic review. BMC Cancer 14:311. https://doi.org/10.1186/1471-2407-14-311

8. Allsop MJ, Taylor S, Mulvey MR, Bennett MI, Bewick BM (2016) Information and communication technology for managing pain in palliative care: a review of the literature. BMJ Support Palliat Care 5:481-489. https://doi.org/10.1136/bmjspcare-2013-000625

9. Strasser F, Blum D, von Moos R, Cathomas R, Ribi K, Aebi S, Betticher D, Hayoz S, Klingbiel D, Brauchli P, Haefner M, Mauri S, Kaasa S, Koeberle D, Swiss Group for Clinical Cancer R (2016) The effect of real-time electronic monitoring of patient-reported symptoms and clinical syndromes in outpatient workflow of medical oncologists: E-MOSAIC, a multicenter cluster-randomized phase III study (SAKK 95/06). Ann Oncol 27(2):324-332. https:// doi.org/10.1093/annonc/mdv576

10. Oldenmenger WH, Sillevis Smitt PA, van Montfort CA, de Raaf PJ, van der Rijt CC (2011) A combined pain consultation and pain education program decreases average and current pain and decreases interference in daily life by pain in oncology outpatients: a randomized controlled trial. Pain 152(11):2632-2639

11. Taylor S, Allsop MJ, Shaw J, Bennett MI, Jones R, Bewick BM (2015) The feasibility of collecting patient reported pain data using a system delivered across four modes of technology. Pain Med 16(11):2212-2213. https://doi.org/10.1111/pme.12811

12. de Raaf PJ, de Klerk C, Timman R, Busschbach JJ, Oldenmenger WH, van der Rijt CC (2013) Systematic monitoring and treatment of physical symptoms to alleviate fatigue in patients with advanced cancer: a randomized controlled trial. J Clin Oncol 31(6):716-723. https://doi.org/10.1200/JCO.2012.44.4216

13. Rolstad S, Adler J, Ryden A (2011) Response burden and questionnaire length: is shorter better? A review and meta-analysis. Value Health 14(8):1101-1108

14. Cleeland CS, Ryan KM (1994) Pain assessment: global use of the brief pain inventory. Ann Acad Med Singap 23(2):129-138

15. Vissers KC, Besse TC, Groot CM, Raats CJ, Rosenbrand CJGM, Vonk SY, Huibers MJW (2008) Richtlijn diagnostiek en behandeling van pijn bij patiënten met kanker. van Zuiden Communications B.V., Alphen aan den Rijn

16. Craig P, Dieppe P, Macintyre S, Michie S, Nazareth I, Petticrew M (2013) Developing and evaluating complex interventions: the new Medical Research Council guidance. Int J Nurs Stud 50(5):587-592

17. Hochstenbach LM, Zwakhalen SM, Courtens AM, van Kleef M, de Witte LP (2016) Feasibility of a mobile and web-based intervention to support self-management in outpatients with cancer pain. Eur J Oncol Nurs 23:97-105

18. van Houtum L, Rijken M, Heijmans M, Groenewegen P (2013) Self-management support needs of patients with chronic illness: do needs for support differ according to the course of illness? Patient Educ Couns 93(3):626-632

19. Netherlands S (2016) ICT gebruik van personen. Accessed 28-09$20162016 \mathrm{http}: / /$ statline.cbs.nl/Statweb/publication/?DM= SLNL\&PA=71098ned\&D1=33,55-59,93-95,97-100,102-104,106$109,112-113,119,124-133 \& \mathrm{D} 2=0,6 \& \mathrm{D} 3=0,1 \& \mathrm{HDR}=$ $\mathrm{G} 2, \mathrm{G} 1 \& \mathrm{STB}=\mathrm{T} \& \mathrm{VW}=\mathrm{T}$ 